\title{
Isolation of an oxalate-resistant Ashbya gossypii strain and its improved riboflavin production
}

\author{
Takashi Sugimoto $\cdot$ Aki Morimoto $\cdot$ \\ Masashi Nariyama · Tatsuya Kato • \\ Enoch Y. Park
}

Received: 16 July 2009/ Accepted: 25 September 2009/Published online: 14 October 2009

(C) The Author(s) 2009. This article is published with open access at Springerlink.com

\begin{abstract}
An oxalate-resistant strain of Ashbya gossypii was naturally isolated from spores grown on an oxalatecontaining medium, and its medium was optimized to improve riboflavin production. Riboflavin production by the resistant strain was three-fold higher than that by the wild-type organism when grown in flask cultures. Medium optimization increased the riboflavin production by the resistant strain to $5 \mathrm{~g}^{-1}$, which was five-fold higher than that obtained by the wild-type strain. The productivity was reproduced in a 3-1 bioreactor. During the early growth phase, the specific activity of isocitrate lyase in the oxalateresistant strain was slightly higher than that in the wildtype strain. Proteomic analysis of the oxalate-resistant strain revealed that the expression of aldose reductase and cobalamin-independent methionine synthase decreased significantly. This is the first report that describes the natural isolation of a riboflavin producer using an antimetabolite-containing medium to enhance the riboflavin production level. This method should also be useful for improving the productivity of other bioproducts since it does not require any mutations or genetic modifications of the microorganism.
\end{abstract}

Keywords Ashbya gossypii - Riboflavin . Antimetabolite $\cdot$ Natural screening

T. Sugimoto · E. Y. Park $(\bowtie)$

Laboratory of Biotechnology, Graduate School of Science and Technology, Shizuoka University, 836 Ohya, Suruga-ku, Shizuoka 422-8529, Japan

e-mail: acypark@ipc.shizuoka.ac.jp

A. Morimoto $\cdot$ M. Nariyama $\cdot$ T. Kato

Laboratory of Biotechnology, Faculty of Agriculture,

Shizuoka University, 836 Ohya, Suruga-ku,

Shizuoka 422-8529, Japan

\section{Introduction}

Riboflavin (vitamin $\mathrm{B}_{2}$ ) is an essential compound for mammals, plants, and microorganisms since it is a precursor of flavin mononucleotide (FMN) and flavin adenine dinucleotide (FAD), which are required as electron acceptors for oxidoreductases. In humans, riboflavin deprivation mainly induces growth retardation and various inflammations. In contrast, excessive intake of riboflavin is harmless. Therefore, this compound is added to many kinds of food and multivitamin supplements as a colorant and/or nutrient.

The filamentous hemiascomycete Ashbya gossypii was first isolated as a plant pathogen [1] and has been characterized as a natural riboflavin producer [24]. Since 1990, A. gossypii has been utilized for the industrial production of riboflavin [20]. Simultaneously, efforts have been made to improve the riboflavin productivity and develop better production media. Previously, we optimized the riboflavin production medium by using wasteactivated bleaching earth (wABE) containing 30-40 $\mathrm{g} \mathrm{l}^{-1}$ of vegetable oils as the carbon source. This led to the production of approximately $1 \mathrm{~g}^{-1}$ of riboflavin from the A. gossypii wild-type strain [11]. Schmidt et al. [17, 18] reported that isocitrate lyase is a key enzyme for riboflavin production when soybean oil is used as the sole carbon source and that this enzyme is strongly inhibited by oxalate or itaconate. Therefore, itaconate and oxalate are useful antimetabolites for screening riboflavin overproducers [14].

In this study, we isolated an oxalate-resistant strain of wild-type A. gossypii by using an oxalate-containing medium as an antimetabolite. This oxalate-resistant strain was not mutated and could produce approximately threefold higher riboflavin levels than the wild-type strain. In an 
optimized medium, the oxalate-resistant strain produced $5 \mathrm{~g} \mathrm{l}^{-1}$ of riboflavin. Enzymatic and proteomic analyses were performed to further characterize the oxalate-resistant strain, and the results are discussed.

\section{Materials and methods}

Strains, media, and growth conditions

A. gossypii ATCC 10895 was used as the wild-type strain $(A g W T)$ and was grown on YD medium ( $\mathrm{pH} 6.8)$ containing $1 \%(\mathrm{w} / \mathrm{v})$ yeast extract (Oriental Yeast Co., Ltd., Tokyo, Japan) and 1\% (w/v) glucose (Wako Pure Chemicals Inc., Ltd., Osaka, Japan) for sporulation and long-term storage at $4^{\circ} \mathrm{C}$. YR medium $(\mathrm{pH} 6.8)$ containing $1 \%(\mathrm{w} / \mathrm{v})$ yeast extract and $1 \%(\mathrm{w} / \mathrm{v})$ rapeseed oil was used as the minimal medium for riboflavin production at a test tube scale. For riboflavin production, we used a seed medium (per liter) consisting of $30 \mathrm{~g}$ corn steep liquor (Wako), $9 \mathrm{~g}$ yeast extract, and $15 \mathrm{~g}$ rapeseed oil ( $\mathrm{pH}$ 6.8). The riboflavin production medium consisted of (per liter) $60 \mathrm{~g}$ corn steep liquor, $30 \mathrm{~g}$ gelatin (Wako), $1.5 \mathrm{~g} \mathrm{KH}_{2} \mathrm{PO}_{4}, 1.5 \mathrm{~g}$ glycine, $2 \mu \mathrm{g} \mathrm{Co}^{2+}, 5 \mu \mathrm{g} \mathrm{Mn}^{2+}, 10 \mu \mathrm{g} \mathrm{Zn}^{2+}, 1 \mu \mathrm{g} \mathrm{Mg}^{2+}$, and $50 \mathrm{~g}$ rapeseed oil ( $\mathrm{pH}$ 6.8). YR medium ( $\mathrm{pH}$ 6.8) containing $50 \mathrm{mM}$ sodium oxalate (Wako) was used to screen oxalateresistant strains.

The flask cultures were performed in 500-ml Erlenmeyer flasks with a working volume of $50 \mathrm{ml}$ of each medium. The flasks were incubated on a rotary shaker (Bio Shaker; Takasaki Inst. Co., Tokyo, Japan) at $220 \mathrm{rpm}$ and $28^{\circ} \mathrm{C}$. Riboflavin production was carried out in a 3-1 bioreactor (Bioneer-300, Marubishi Co., Ltd., Tokyo, Japan) with a working volume of $1.5-1$ of production medium. The agitation and aeration rates were $600 \mathrm{rpm}$ and $1 \mathrm{vvm}$, respectively. The inoculum dose in each culture was $10 \%$ $(\mathrm{v} / \mathrm{v})$.

Spore isolation and selection of an oxalate-resistant colony

A. gossypii sporulation was induced in mycelia grown on a YD agar plate at $28^{\circ} \mathrm{C}$ for 1 week. The collected mycelia were suspended in $0.5 \mathrm{ml}$ of sterile distilled water. The cell wall was degraded by adding $0.2 \%$ (w/v) Zymolyase 20T (Seikagaku Co., Tokyo, Japan) and incubating for $30 \mathrm{~min}$ at $37^{\circ} \mathrm{C}$ with gentle agitation. The solution was centrifuged at $2,700 \mathrm{~g}$ for $5 \mathrm{~min}$, and the pellet was suspended in $1 \mathrm{ml}$ of sterile distilled water containing $0.03 \%$ Triton X-100. It was washed twice under the same conditions. The hydrophobic spores were resuspended in $0.5 \mathrm{ml}$ of the same $0.03 \%$ Triton $\mathrm{X}-100$ solution, followed by the addition of $0.1 \mathrm{ml}$ glycerol. The spores were then stored at $-80^{\circ} \mathrm{C}$ in a freezer until further use.

Oxalate-resistant colony isolation was carried out by plating $1 \times 10^{3}$ spores of the A. gossypii wild-type strain onto a screening medium. The plate was incubated at $28^{\circ} \mathrm{C}$ for 1 week, and single yellow colonies were transferred onto fresh screening medium.

Enzyme assay

A crude enzyme solution was prepared as described below. The mycelia of $A g \mathrm{WT}$ and oxalate-resistant strains grown in YR medium were harvested by filtration through filter paper no. 5A (Advantec, Tokyo, Japan). One gram of wet mycelia was suspended in $5 \mathrm{ml}$ of cooled buffer containing $50 \mathrm{mM}$ imidazole/ $\mathrm{HCl}$ buffer ( $\mathrm{pH} 7.5), 10 \mathrm{mM} \mathrm{KCl}, 1 \mathrm{mM}$ EDTA, $5 \mathrm{mM} \mathrm{MgSO}_{4}, 5 \mathrm{mM}$ dithiothreitol (DTT), $1 \mathrm{mM}$ phenylmethylsulfonyl fluoride (PMSF), and $30 \%(\mathrm{v} / \mathrm{v})$ glycerol. The mycelia were sonicated three times at $40 \mathrm{~W}$ for $30 \mathrm{~s}$ with 1-min intervals on ice using an ultrasonicator (Sonics and Materials Inc., Newtown, CT). The resulting homogenate was centrifuged at $14,000 \mathrm{~g}$ for $30 \mathrm{~min}$ at $4^{\circ} \mathrm{C}$, and the supernatant was used for the enzyme assay.

The isocitrate lyase (ICL1) activity was measured according to the method described by Schmidt et al. [17]. The enzyme assay was carried out in a final volume of $1 \mathrm{ml}$ containing $25 \mathrm{mM}$ imidazole/ $\mathrm{HCl}$ buffer $(\mathrm{pH} 7.0), 4 \mathrm{mM}$ phenylhydrazine hydrochloride (Wako), $4 \mathrm{mM}$ threo-DLisocitrate (Sigma-Aldrich Co., St. Louis, MO), $5 \mathrm{mM}$ $\mathrm{MgCl}_{2}, 1 \mathrm{mM}$ EDTA, $5 \mathrm{mM}$ DTT, and crude enzyme solution. The reaction was initiated by adding isocitrate at $30^{\circ} \mathrm{C}$. Formation of glyoxylate phenylhydrazone was measured by recording the absorbance at $324 \mathrm{~nm}$ ( $\varepsilon=14,630 \mathrm{M}^{-1} \mathrm{~cm}^{-1}$ ). One unit of enzyme activity was defined as the amount of enzyme required to form $1 \mu \mathrm{mol}$ of glyoxylate phenylhydrazone per min. The total protein concentration was determined by the Bradford method using a protein assay kit (Bio-Rad Laboratories, Inc., Hercules, CA) with bovine serum albumin (Sigma) as the standard.

Optimization of the riboflavin production medium

The production medium was optimized using the two-level and three-level factor (Box-Behnken) designs. Important factors in riboflavin production were extracted by the twolevel factor design. The extracted components were optimized by the Box-Behnken design. Statistical analysis was performed with STATISTICA (StatSoft, Inc., Tulsa, OK), and the regression of the parameters was solved by Mathcad 2001 Professional (Mathsoft Engineering and Education, Inc., Cambridge, MA). 
Proteome analysis

The $A g \mathrm{WT}$ and oxalate-resistant strains were grown in gelatin-containing riboflavin production medium in 500-ml Erlenmeyer flasks at $28^{\circ} \mathrm{C}$ for 4 days. The mycelia were harvested, washed twice with sterile distilled water, and suspended in $50 \mathrm{mM}$ potassium phosphate buffer ( $\mathrm{pH}$ 6.0). Subsequently, the mycelia were sonicated on ice five times at $40 \mathrm{~W}$ for $30 \mathrm{~s}$ with 1-min intervals using an ultrasonicator (Sonics and Materials) to release the intracellular soluble proteins. The sample was centrifuged at $20,000 \mathrm{~g}$ and $4^{\circ} \mathrm{C}$ for $5 \mathrm{~min}$, and the supernatant containing the soluble proteins was used for two-dimensional electrophoresis proteome analysis (performed at Shimadzu Techno-Research Inc., Kyoto, Japan).

\section{Analytical methods}

The riboflavin and residual oil concentrations were measured according to the method described by Park and Ming [13]. The dry cell weight was measured as follows: the mycelia from the culture broth were harvested using filter paper no. 5A (Advantec). The mycelia paste was dried overnight in an oven at $105^{\circ} \mathrm{C}$, and the difference in the weights was calculated and expressed as the dry cell weight in $\mathrm{g} 1^{-1}$.

\section{Results}

Isolation of an oxalate-resistant A. gossypii strain and its riboflavin production

An oxalate-resistant riboflavin overproducer was isolated from $A g \mathrm{WT}$ spores using $50 \mathrm{mM}$ of oxalate as the antimetabolite. One colony from approximately 50,000 spores showed an intense yellowish color. This was isolated and designated as the oxalate-resistant strain (AgOXA50). Most of the other colonies grown on the oxalate-containing medium were white (data not shown).
The resistance of the $A g$ OXA50 strain to oxalate was investigated by growing the strain on a rotary shaker for 5 days on YR medium containing 0 or $50 \mathrm{mM}$ of oxalate. In the case of the $A g \mathrm{WT}$ strain, the addition of $50 \mathrm{mM}$ oxalate resulted in a reduction in both the maximum riboflavin concentration and riboflavin yield $\left(Y_{\mathrm{p} / \mathrm{x}}\right)$ by 95 and $88 \%$, respectively (Table 1$)$. On the other hand, the riboflavin concentration of $\mathrm{AgOXA50}$ in the absence of oxalate was lower than that of the $A g \mathrm{WT}$ strain, but it in the presence of oxalate was 7.4-fold to that of the $A g$ WT strain. When the oxalate-containing medium was used, the dry cell weight of the $A g \mathrm{WT}$ strain decreased 59\%, while that of the AgOXA50 strain was not influenced by oxalate addition. The cellular riboflavin yield $\left(Y_{\mathrm{p} / \mathrm{x}}\right)$ increased to approximately three times that of the $A g \mathrm{WT}$ strain. These results indicate that the $A g \mathrm{OXA} 50$ strain was certainly resistant to oxalate.

The AgOXA50 strain was cultured in shake flasks on production medium without oxalate. The riboflavin concentration of the AgOXA50 strain was $3.6 \mathrm{~g} \mathrm{l}^{-1}$, which was approximately three-fold higher than that of $A g$ WT (Fig. 1). Moreover, the maximum riboflavin production rate of the $A g$ OXA50 strain was $1.40 \mathrm{~g} \mathrm{l}^{-1} \mathrm{~d}^{-1}$, which was approximately four-fold higher than that of the wild-type strain $\left(0.36 \mathrm{~g} \mathrm{l}^{-1} \mathrm{~d}^{-1}\right)$. This result suggests that the naturally isolated oxalate-resistant strain can be used as a potential riboflavin overproducer.

Characterization of the $A g \mathrm{OXA50}$ strain: isocitrate lyase assay and proteome analysis

The isocitrate lyase activity of the AgOXA50 strain on the 1st culture day was slightly higher than that of $A g \mathrm{WT}$, but there were no significant differences between the $A g \mathrm{WT}$ and $A g$ OXA50 strains (Fig. 2).

Subsequently, proteomic analysis was carried out to analyze the high riboflavin productivity of the $A g \mathrm{OXA50}$ strain. Three spots were identified that corresponded to cobalamin-independent methionine synthase and another

Table 1 Comparison of the riboflavin production levels of the AgWT and AgOXA50 strains on YR medium with and without oxalate

\begin{tabular}{|c|c|c|c|c|}
\hline \multirow{2}{*}{$\begin{array}{l}\text { Strain } \\
\text { Oxalate concentration }(\mathrm{mM})\end{array}$} & \multicolumn{2}{|l|}{$A g \mathrm{WT}$} & \multicolumn{2}{|l|}{ AgOXA50 } \\
\hline & 0 & 50 & 0 & 50 \\
\hline Maximum riboflavin concentration $\left(\mathrm{mg}^{-1}\right)$ & $357 \pm 10.4(5)^{\mathrm{a}}$ & $18.0 \pm 1.16(5)$ & $232 \pm 18.3(5)$ & $133 \pm 2.56$ \\
\hline Maximum dry cell weight $\left(\mathrm{g} \mathrm{l}^{-1}\right)$ & $5.1 \pm 0.20(1)$ & $3.0 \pm 0.12(4)$ & $5.8 \pm 0.17(1)$ & $5.6 \pm 0.10(1)$ \\
\hline$Y_{\mathrm{p} / \mathrm{x}}\left(\mathrm{mg} \mathrm{g}^{-1}\right)^{\mathrm{b}}$ & $70 \pm 0.79$ & $8.2 \pm 2.5$ & $40 \pm 3.8$ & $24 \pm 0.44$ \\
\hline
\end{tabular}




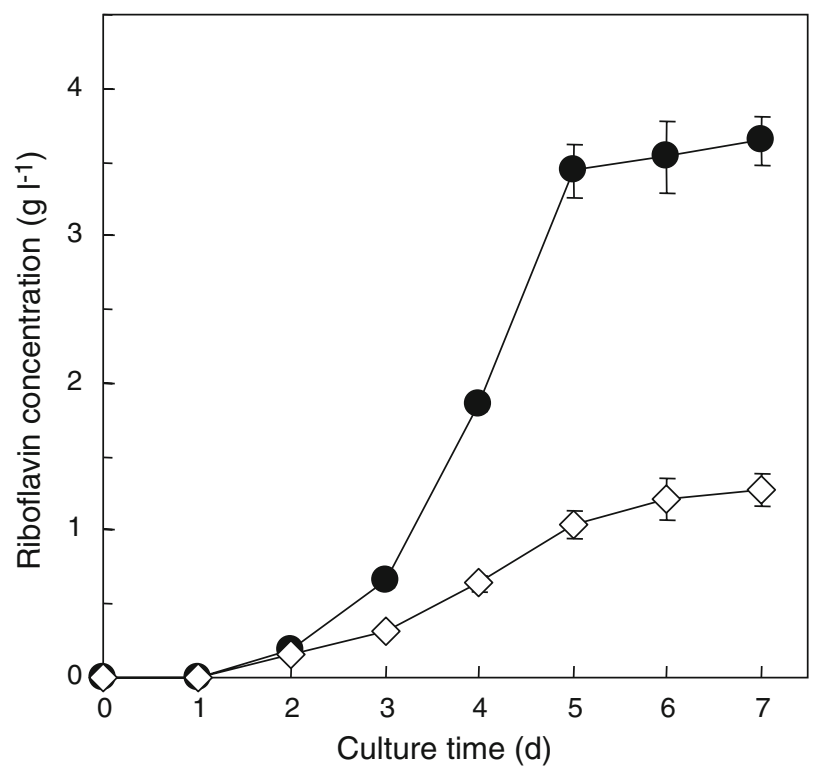

Fig. 1 Comparison of the riboflavin production by the wild-type strain (AgWT; open rhombuses) and oxalate-resistant strain (AgOXA50; closed circles) in a gelatin-containing riboflavin production medium. The cultivations were carried out in a $500-\mathrm{ml}$ Erlenmeyer flask with a working volume of $50 \mathrm{ml}$. Both strains were cultured for 7 days in triplicates. The error bars indicate the standard deviation

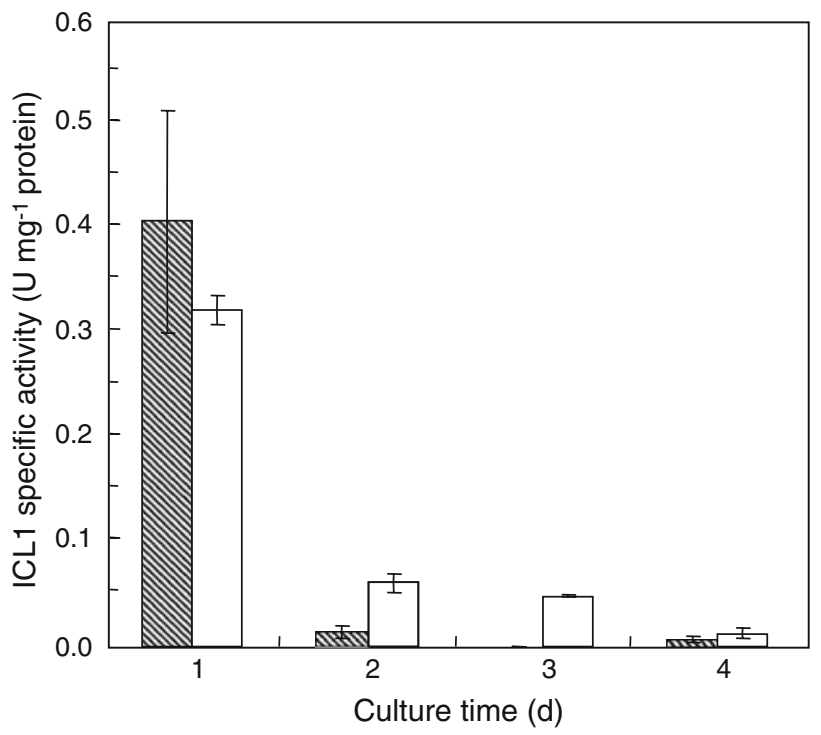

Fig. 2 Comparison of the specific isocitrate lyase activities of the AgWT (opened bars) and AgOXA50 (slanted bars) strains. Both strains were cultured for 4 days in a 500-ml Erlenmeyer flask with $50 \mathrm{ml}$ of YR medium. The experiments were performed in triplicate. The error bars indicate the standard deviation

was identified as aldose reductase (Table 2). The expression level of these proteins in the AgOXA50 strain was sixfold lower than the corresponding levels in $A g \mathrm{WT}$. On the other hand, BLAST analysis of the Ashbya gossypii sequence (http://ashbya.genome.duke.edu/) revealed only one spot that had a six-fold higher expression level and did not match with any A. gossypii proteins [4].

Optimization of the medium for the AgOXA50 strain

The two-level factor design experiment identified the effective factors in the riboflavin production medium as being corn steep liquor, rapeseed oil, and glycine. Subsequently, the optimized concentrations of the three above-mentioned components were determined using the Box-Behnken design (Table 3). The combined effects of the three nutrients on the riboflavin concentration are shown in Fig. 3. The corn steep liquor concentration in the medium was optimized in the range of 55-65 $\mathrm{g} \mathrm{l}^{-1}$, but rapeseed oil was not involved in the riboflavin production (Fig. 3a). The glycine concentration was optimized to less than $10 \mathrm{~g} \mathrm{l}^{-1}$ (Fig. 3b, c), in spite of glycine being a direct precursor of riboflavin in A. gossypii [12]. The following regression equation for the three nutrients $(X$, rapeseed oil; $Y$, corn steep liquor; $Z$, glycine; each unit is expressed in $\mathrm{g}^{-1}$ ) was obtained: $F(X, Y, Z)=-4.17607+0.02614 X+$ $0.23584 Y+0.20084 Z-0.00014 X Y-0.00149 X Z-$ $0.00130 Y Z-0.00002 X^{2}-0.00174 Y^{2}-0.00381 Z^{2}$.

The optimized concentrations of corn steep liquor, rapeseed oil, and glycine were determined to be $62.3,100$, and $4.0 \mathrm{~g} \mathrm{l}^{-1}$. The other medium components were $1.5 \mathrm{~g}$ $\mathrm{KH}_{2} \mathrm{PO}_{4}, 2 \mu \mathrm{g} \mathrm{Co}{ }^{2+}, 5 \mu \mathrm{g} \mathrm{Mn}{ }^{2+}, 10 \mu \mathrm{g} \mathrm{Zn}^{2+}$, and $1 \mu \mathrm{g} \mathrm{Mg}^{2+}$ (pH 6.8). Using this optimized medium, we expected a riboflavin production level of $5.1 \mathrm{~g} \mathrm{l}^{-1}$. In a flask culture of the AgOXA50 strain, the riboflavin concentration was $4.9 \mathrm{~g} \mathrm{l}^{-1}$, which was close to the theoretically expected concentration. Since gelatin was excluded from the optimized medium, the glycine concentration in the region from 0 to $4 \mathrm{~g} \mathrm{l}^{-1}$ was reoptimized and determined to be $3 \mathrm{~g} \mathrm{l}^{-1}$. Without the addition of glycine, the riboflavin concentration was only $1.2 \mathrm{~g} \mathrm{l}^{-1}$, but increased with the increase of glycine concentration (data not shown). The optimized glycine concentration was decided to be $3 \mathrm{~g} \mathrm{l}^{-1}$. Using this optimized medium, the riboflavin concentration increased to $5.2 \mathrm{~g} \mathrm{l}^{-1}$. Interestingly, when the optimized medium without gelatin was used to culture the AgOXA50 strain, the riboflavin production improved and was approximately $40 \%$ higher than that obtained (3.6 $\mathrm{g} \mathrm{l}^{-1}$ of riboflavin concentration) in the conventional gelatin-containing medium (data not shown).

Riboflavin production using the AgOXA50 strain was carried out in a 3-1 scale bioreactor using the optimized production medium. The riboflavin concentration in the AgOXA50 culture was $4.4 \mathrm{~g} \mathrm{l}^{-1}$ (Fig. 4). Use of the optimized medium with the $A g \mathrm{WT}$ strain led to an approximately two-fold higher riboflavin production level than that obtained with the conventional gelatin-containing medium. 
Table 2 Use of proteomic analysis to identify proteins that exhibit large differences in their expression levels between the $\mathrm{AgWT}$ and $\mathrm{AgOXA50}$ strains $^{\mathrm{a}}$

\begin{tabular}{lllll}
\hline Spot & Protein & \% Sequence coverage & Expect & $\begin{array}{l}\text { Expression level } \\
(A g O X A 50 / A g W T)^{\mathrm{b}}\end{array}$ \\
\hline $6501 \mathrm{R}$ & Aldose reductase & 54 & $6.8 \mathrm{e}-018$ & 6.4 -fold decrease \\
$6704 \mathrm{R}$ & Cobalamin-independent methionine synthase & 40 & $3.4 \mathrm{e}-019$ & 5.1 -fold decrease \\
$6801 \mathrm{R}$ & Cobalamin-independent methionine synthase & 58 & $1.4 \mathrm{e}-028$ & 6.9 -fold decrease \\
$6804 \mathrm{R}$ & Cobalamin-independent methionine synthase & 59 & $2.7 \mathrm{e}-034$ & $14-$ fold decrease \\
$4006 \mathrm{R}$ & Not matched & - & - & 6.1 -fold increase \\
\hline
\end{tabular}

${ }^{a}$ Both strains were grown in flask cultures on a riboflavin production medium for 4 days

b The selected spots had an expression level that differed by more than six-fold between the two strains

Table 3 Box-Behnken experimental design

\begin{tabular}{lclll}
\hline $\begin{array}{l}\text { Experiment } \\
\text { umber }\end{array}$ & $\begin{array}{l}\text { Rapeseed } \\
\text { oil }\left(\mathrm{g} \mathrm{l}^{-1}\right)\end{array}$ & $\begin{array}{l}\text { Corn steep } \\
\text { liquor } \\
\left(\mathrm{g} \mathrm{l}^{-1}\right)\end{array}$ & $\begin{array}{l}\text { Glycine } \\
\left(\mathrm{g} \mathrm{l}^{-1}\right)\end{array}$ & $\begin{array}{l}\text { Riboflavin } \\
\text { concentration } \\
\left(\mathrm{g} \mathrm{l}^{-1}\right)^{\mathrm{a}}\end{array}$ \\
\hline 1 & 60 & 40 & 9 & 3.9 \\
2 & 100 & 40 & 9 & 3.8 \\
3 & 60 & 80 & 9 & 4.3 \\
4 & 100 & 80 & 9 & 4.0 \\
5 & 60 & 60 & 4 & 4.6 \\
6 & 100 & 60 & 4 & 5.2 \\
7 & 60 & 60 & 14 & 4.3 \\
8 & 100 & 60 & 14 & 4.3 \\
9 & 80 & 40 & 4 & 4.1 \\
10 & 80 & 80 & 4 & 4.5 \\
11 & 80 & 40 & 14 & 3.6 \\
12 & 80 & 80 & 14 & 3.4 \\
13 & 80 & 80 & 9 & 4.6 \\
14 & 80 & 80 & 9 & 4.7 \\
15 & 80 & 80 & 9 & 4.8 \\
\hline
\end{tabular}

${ }^{a}$ The concentration was measured from the 8th day culture broth in a flask culture

\section{Discussion}

Spore isolation is an effective method for screening strains with desirable traits from multinucleate microorganisms. In this study, a natural oxalate-resistant $A$. gossypii strain (AgOXA50) was successfully obtained by single colony isolation using an antimetabolite-containing medium. Oxalate is a C-2 compound with two symmetrical carboxyl residues and is produced from glyoxylate by glyoxylate oxidase. It is one of the strongest inhibitors of isocitrate lyase in A. gossypii [18]. Itaconate, which has been mainly used as an antimetabolite for screening riboflavin overproducers $[14,18]$, also has two carboxyl residues, but the mode of inhibition differs from that of oxalate. The isocitrate lyase from the resistant strains may exhibit higher activity and/or substrate specificity than the corresponding enzyme from the wild-type strain due to differences in their mode of inhibition. The activity in the AgOXA50 strain was similar to that in the wild-type strain, while the activity of itaconate-resistant A. gossypii was approximately three-fold higher than that in the wild-type strain [23]. This suggests that the AgOXA50 strain is required to precisely investigate the substrate specificity of isocitrate lyase.

Riboflavin production by the AgOXA50 strain was approximately three-fold higher than that by the AgWT strain on a gelatin-containing riboflavin production medium (Fig. 1). Proteomic analysis revealed that the expression of cobalamin-independent methionine synthase and aldose reductase was significantly decreased (Table 2). Methionine synthase catalyses the formation of methionine by transferring a methyl group from methyltetrahydrofolate to homocysteine without using cobalamin (vitamin $\mathrm{B}_{12}$ ) as a cofactor. To investigate the results from proteomic analysis, cobalamin-independent methionine synthase was disrupted in the $A g$ WT strain. The growth curve of the disruptant was similar to that of the AgOXA50 strain with little improvement in the riboflavin production in comparison to the $A g$ WT strain (data not shown). Garcia et al. [6] reported that a reduction in the expression level of methionine synthase affected fungal growth and/or morphological alterations due to changes in the intracellular amount of $S$-adenosylmethionine in Mucor racemosus. Another enzyme, aldose reductase, a member of the aldo/ keto reductase family, catalyses the first step of xylose metabolism in which glucose is converted to sorbitol. In mammalian cells and the yeast Saccharomyces cerevisiae, an increase in the transcriptional level and activity of aldose reductase are induced by hyperosmolarity stress, resulting in elevated intracellular levels of sorbitol, which is an osmolyte [2,5]. The osmotic phenotypes showed little change in comparison to the $A g \mathrm{WT}$ and $A g \mathrm{OXA} 50$ strains grown on a hyperosmolarity stress plate medium (data not shown). 


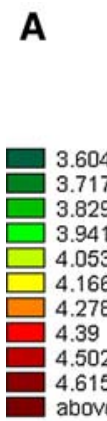

B

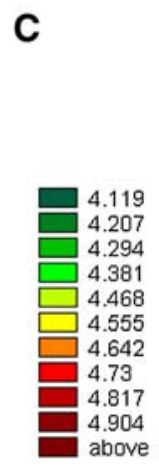

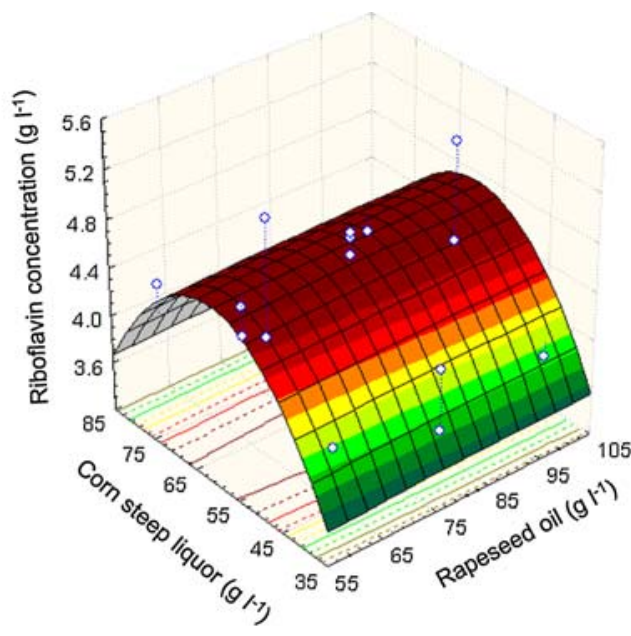
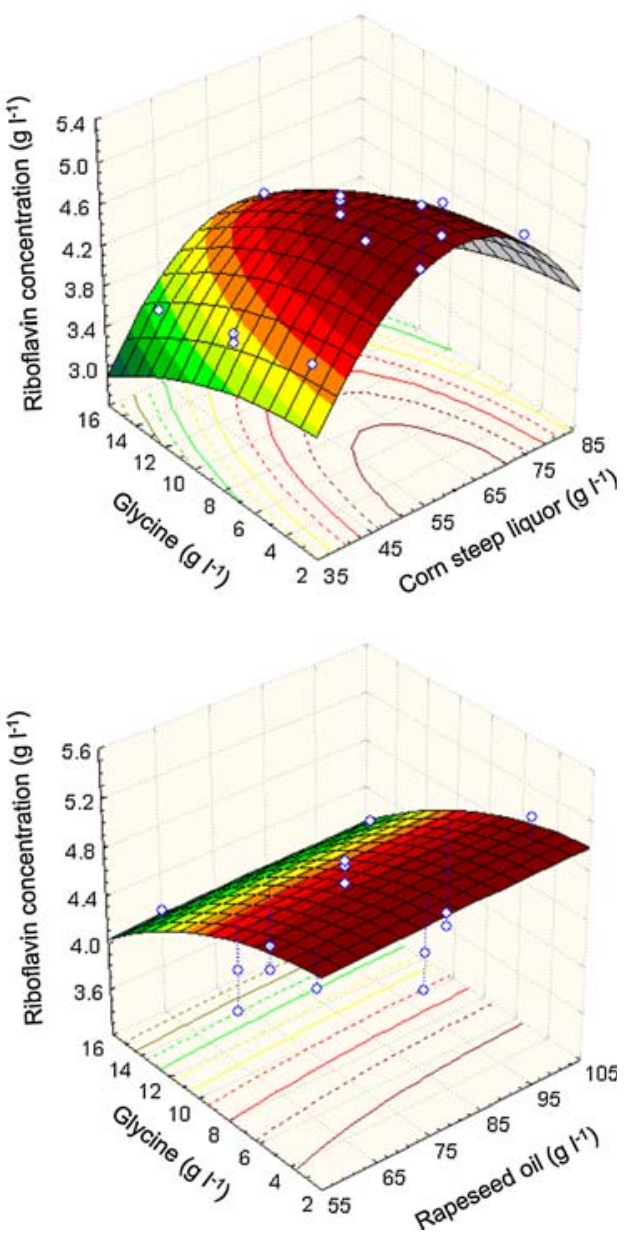

Fig. 3 Three-dimensional response surface plot for the combined effect of corn steep liquor and rapeseed oil (a), corn steep liquor and glycine (b), and rapeseed oil and glycine (c) on riboflavin production during the culture of the AgOXA50 strain. The riboflavin concentration was measured on the 8th day

To improve the riboflavin production levels in the AgOXA50 strain, we redesigned the medium for riboflavin production by using experimental designs.

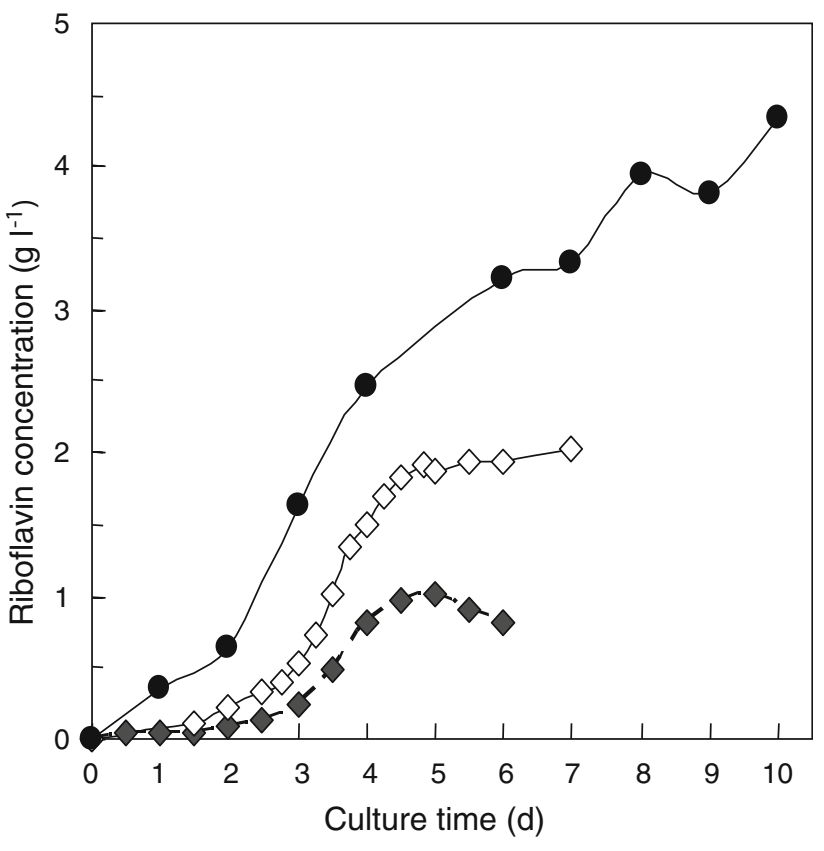

Fig. 4 Comparison of riboflavin production in the $A g W T$ and $A g$ OXA50 strains in a 3-1 bioreactor. The $A g \mathrm{WT}$ strain was cultured on a gelatin-containing medium (closed rhombuses) and an optimized medium (opened rhombuses). The AgOXA50 strain was cultured on the optimized medium (closed circles)

The Box-Behnken design increased the corn steep liquor concentration and decreased the glycine concentration to enhance riboflavin production (Table 3). Although glycine contributes directly to riboflavin biosynthesis [15], the AgOXA50 strain did not require high amounts of the precursor (Fig. $3 b, c)$. It seems that the AgOXA50 strain acquired the ability to accumulate glycine intracellularly, similar to the overexpression of threonine aldolase and/or suppressed expression of serine hydroxymethyltransferase, enzymes that catalyze the biosynthesis of glycine from threonine and serine from glycine, respectively $[12,16]$.

The optimal medium composition for riboflavin production by the $A g \mathrm{OXA} 50$ strain was determined, and more than $5 \mathrm{~g} \mathrm{l}^{-1}$ of riboflavin was produced, which was approximately five-fold higher than the amount produced by $A g$ WT. Gelatin was excluded in the newly designed optimized medium. Gelatin, which is an abundant nitrogen source from animals, can empirically induce dramatic hyphal growth in A. gossypii during the initial stages of culture. However, plant-derived medium components are required for the industrial production of useful bioproducts. Removal of expensive gelatin from the optimized medium also helps in reducing the operation costs Table 4.

With the progress of strain improvement, riboflavin production as high as $1,015 \mathrm{~g} \mathrm{l}^{-1}$ has been reached [3]. The microbial production of riboflavin was reviewed in Lim et al. 
Table 4 Comparison of riboflavin production by Ashbya gossypii

\begin{tabular}{|c|c|c|c|c|c|}
\hline Strain & Carbon source & Nitrogen source & $\begin{array}{l}\text { Maximum } \\
\text { riboflavin } \\
\text { concentration }\end{array}$ & $\begin{array}{l}\text { Culture } \\
\text { time }(d)\end{array}$ & Reference \\
\hline Wild-type & Glucose & $\begin{array}{l}\text { Asparagine, glycine, } \\
\text { tyrosine }\end{array}$ & $0.4-1.0 \mathrm{~g} / 1$ & - & {$[8,19]$} \\
\hline Wild-type & Waste $\mathrm{ABE}^{\mathrm{b}}$ & CSL, gelatin & $1.1 \mathrm{~g} / 1$ & 6.0 & [11] \\
\hline Wild-type & Soybean oil, bone fat & CSL, gelatin & $5.0 \mathrm{~g} / 1$ & 8.0 & [22] \\
\hline \multicolumn{6}{|l|}{ Conventional mutation } \\
\hline ZP4 (Itaconate resistance) & $\mathrm{ABE}$ adsorbing rapeseed oil & CSL, gelatin, glycine & $8.7 \mathrm{~g} / 1$ & 5.0 & [14] \\
\hline 13a (Itaconate resistance) & $\mathrm{ABE}$ containing rapeseed oil & $\begin{array}{l}\text { CSL, yeast extract, gelatin, } \\
\text { glycine }\end{array}$ & $8.7 \mathrm{~g} / 1$ & 6.0 & [23] \\
\hline AgOXA50 (Oxalate resistance) & Rapeseed oil & CSL, glycine & $5.2 \mathrm{~g} / 1$ & 8.0 & This study \\
\hline \multicolumn{6}{|l|}{ Genetic modification } \\
\hline $\begin{array}{l}\text { Threonine aldolase gene overexpressed } \\
\text { strain }(\mathrm{pAG} 2303 G L Y 1)^{\mathrm{a}}\end{array}$ & Glucose & Yeast extract & $33 \mathrm{mg} / \mathrm{l}(37)^{\mathrm{d}}$ & 2.4 & [12] \\
\hline $\begin{array}{l}\text { Serine hydroxymethyl transferase gene } \\
\text { disrupted strain }(\triangle S H M 2-1 / 2)\end{array}$ & Glucose & Yeast extract & $96 \mathrm{mg} / \mathrm{l}(9)^{\mathrm{e}}$ & 3.0 & [16] \\
\hline \multirow{2}{*}{$\begin{array}{l}\text { Alanine:glyoxylate aminotransferase } \\
\text { gene overexpressed strain } \\
(\text { pYPKTPAT1-1) }\end{array}$} & Glucose & Yeast extract & $20 \mathrm{mg} / \mathrm{l}(15)^{\mathrm{d}}$ & 3.0 & \multirow[t]{2}{*}{ [9] } \\
\hline & Rapeseed oil & Yeast extract & $150 \mathrm{mg} / \mathrm{l}(100)^{\mathrm{d}}$ & 4.0 & \\
\hline $\begin{array}{l}\text { Site-directed mutated } \mathrm{PRPP}^{\mathrm{b}} \\
\text { amidotransferase gene overexpressed } \\
\text { strain }(G P D \text {-ade } 4-W V Q)\end{array}$ & Glucose & Yeast extract & $228 \mathrm{mg} / \mathrm{l}(25)^{\mathrm{d}}$ & 3.0 & [7] \\
\hline $\begin{array}{l}\text { Malate synthase gene overexpressed } \\
\text { strain (AgMLS1) }\end{array}$ & Rapeseed oil & CSL, gelatin, glycine & $700 \mathrm{mg} / \mathrm{l}(400)^{\mathrm{d}}$ & 6.0 & [21] \\
\hline \multicolumn{6}{|l|}{${ }^{a}$ Used plasmids for transformation } \\
\hline \multicolumn{6}{|c|}{ b PRPP, phosphoribosyl pyrophosphate amidotransferase } \\
\hline \multicolumn{6}{|c|}{ c Waste activated bleaching earth containing vegetable oil discharged from oil refinery process } \\
\hline \multicolumn{6}{|c|}{${ }^{\mathrm{d}}$ Riboflavin concentration of transformant harboring control plasmid } \\
\hline \multicolumn{6}{|c|}{ e Riboflavin concentration of the wild-type strain } \\
\hline
\end{tabular}

[10]. Recently, A. gossypii has been applied to biorefinery of waste activate bleaching earth (ABE) for riboflavin production. Conventional mutation using itaconate as an antimetabolite was adopted to improve riboflavin productivity, resulting in an eight-fold increase compared to wildtype strain [9, 13]. However, sometimes these mutants are unstable in riboflavin productivity. UV-induced mutants lost the riboflavin-producing ability within 2 years (data not shown). Therefore, this study tried to isolate the riboflavin overproducer by means of the natural screening using oxalate as antimetabolite. The oxalate-resistant AgOXA50 strain was stable for riboflavin production for more than 2 years. If a fed-bed culture of this AgOXA50 strain was adopted, a riboflavin yield of more than $5 \mathrm{~g} \mathrm{l}^{-1}$ would be reached. From the metabolic viewpoint of riboflavin overproduction, many researchers have investigated the effect of key enzymes on riboflavin production, such as threonine aldolase [12], alanine: glyoxylate aminotransferase [9], phosphoribosyl pyrophosphate amidotransfersase [7], and malate synthase [21]. On the other hand, when serine hydroxymethyl transferase was disrupted, the riboflavin yield also increased ten-fold [16]. With the progress of these metabolic, biosynthetic, and genetic developments, the 8-10 days of long culture time will be shortened, resulting in improving riboflavin productivity.

In this study, oxalate was used to isolate a riboflavin overproducer of Ashbya gossypii. The oxalate-resistant strain did not require expensive gelatin as the nitrogen source, and it could be replaced by the cheaper plantderived corn steep liquor. This kind of natural isolation with a plant-derived production medium may lead to the development of an industrialized strain that would be a non-genetically modified organism.

Acknowledgments This study was supported by a Comprehensive Support Programs for Creation of Regional Innovation in Japan Science and Technology Agency.

Open Access This article is distributed under the terms of the Creative Commons Attribution Noncommercial License which permits any noncommercial use, distribution, and reproduction in any medium, provided the original author(s) and source are credited. 


\section{References}

1. Ashby SF, Nowell N (1926) The fungi of stigmatomycosis. Ann Bot 40:69-83

2. Burg MB, Kwon ED, Kültz D (1996) Osmotic regulation of gene expression. FASEB J 10:1598-1606

3. Chotani GK, Dodge TC, Gaertner AL, Arbige MV (2007) Industrial biotechnology: discovery to delivery. In: Kent JA (ed) Kent and Riegel's handbook of industrial chemistry and biotechnology, vol 2, 11th edn. Springer, New York, p 1364

4. Dietrich FS, Voegeli S, Brachat S, Lerch A, Gates K, Steiner S, Mohr C, Pöhlmann R, Luedi P, Choi S, Wing RA, Flavier A, Gaffney TD, Philippsen P (2004) The Ashbya gossypii genome as a tool for mapping the ancient Saccharomyces cerevisiae genome. Science 304:304-307

5. Garay-Arroyo A, Covarrubias AA (1999) Three genes whose expression is induced by stress in Saccharomyces cerevisiae. Yeast 15:879-892

6. Garcia JR, Hiatt WR, Peters J, Sypherd PS (1980) S-Adenosylmethionine levels and protein methylation during morphogenesis of Mucor racemosus. J Bacteriol 142:196-201

7. Jiménez A, Santos MA, Pompejus M, Revuelta JL (2005) Metabolic engineering of the purine pathway for riboflavin production in Ashbya gossypii. Appl Environ Microbiol 71(10):5743-5751

8. Kaplan L, Demain AL (1970) Nutritional studies on riboflavin overproduction by Ashbya gossypii. In: Ahearn DG (ed) Recent trends in yeast research. Georgia State University, Atlanta, pp 137-159

9. Kato T, Park EY (2004) Expression of alanine: glyoxylate aminotransferase gene from Saccharomyces cerevisiae in Ashbya gossypii. Appl Microbiol Biotechnol 71:46-52

10. Lim SH, Choi JS, Park EY (2001) Microbial production of riboflavin using riboflavin overproducers, Ashbya gossypii, Bacillus subtilis, and Candida famate: an overview. Biotechnol Bioproc Eng 6:75-88

11. Ming H, Pizarro Ana VL, Park EY (2003) Application of waste activated bleaching earth containing rapeseed oil on riboflavin production in the culture of Ashbya gossypii. Biotechnol Prog 19:410-417

12. Monschau N, Sahm H, Stahmann K-P (1998) Threonine aldolase overexpression plus threonine supplementation enhanced riboflavin production in Ashbya gossypii. Appl Environ Microbiol 64:4283-4290
13. Park EY, Ming H (2004) Oxidation of rapeseed oil in waste activated bleaching earth and its effect on riboflavin production in culture of Ashbya gossypii. J Biosci Bioeng 97:59-64

14. Park EY, Zhang JH, Tajima S, Dwiarti L (2007) Isolation of Ashbya gossypii mutant for an improved riboflavin production targeting for biorefinery technology. J Appl Microbiol 103:468476

15. Plaut GWE (1954) Biosynthesis of riboflavin. I. Incorporation of $\mathrm{C}^{14}$-labeled compounds into rings $\mathrm{B}$ and $\mathrm{C}$. J Biol Chem 208:513-520

16. Schlüpen C, Santos MA, Weber U, de Graaf A, Revuelta JL, Stahmann K-P (2003) Disruption of the SHM2 gene, encoding one of two serine hydroxymethyltransferase isoenzymes, reduces the flux from glycine to serine in Ashbya gossypii. Biochem $\mathrm{J}$ 369:263-273

17. Schmidt G, Stahmann K-P, Kaesler B, Sahm H (1996) Correlation of isocitrate lyase activity and riboflavin formation in the riboflavin overproducer Ashbya gossypii. Microbiology 142:419426

18. Schmidt G, Stahmann K-P, Sahm H (1996) Inhibition of purified isocitrate lyase identified itaconate and oxalate as potential antimetabolites for the riboflavin overproducer Ashbya gossypii. Microbiology 142:411-417

19. Smith CG, Smith GA, Papadoupoulou Z (1961) Effect of surface active agents on the biosynthesis of riboflavin by Ashbya gossypii. Biochem Biophys Acta 47:344-349

20. Stahmann K-P, Revuelta JL, Seulberger H (2000) Three biotechnical processes using Ashbya gossypii, Candida famata, or Bacillus subtilis compete with chemical riboflavin production. Appl Microbiol Biotechnol 53:509-516

21. Sugimoto T, Kanamasa S, Kato T, Park EY (2009) Importance of malate synthase in the glyoxylate cycle of Ashbya gossypii for the efficient production of riboflavin. Appl Microbiol Biotechnol 83:529-539

22. Szczesniak T, Karabin L, Szczepankowska M, Wituch K (1971) Biosynthesis of Riboflavin by Ashbya gossypii. Part I. The influence of fats of the animal origin on the riboflavin production. Acta Microbiol Pol B 3:29-34

23. Tajima S, Itoh Y, Sugimoto T, Kato T, Park EY (2009) Increased riboflavin production from activated bleaching earth by a mutant strain of Ashbya gossypii. J Biosci Bioeng (in press)

24. Wickerham LJ, Flickinger MH, Johnsten RM (1946) The production of riboflavin by Ashbya gossypii. Arch Biochem 9:95-98 